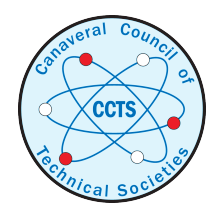

Mar 7th, 8:00 AM

\title{
A Methodology to Analyze and Evaluate Critical Human Performance
}

\author{
M. A. Barone \\ Brown Engineering Company, Inc.
}

Follow this and additional works at: https://commons.erau.edu/space-congress-proceedings

\section{Scholarly Commons Citation}

Barone, M. A., "A Methodology to Analyze and Evaluate Critical Human Performance" (1966). The Space Congress ${ }^{\circledR}$ Proceedings. 3.

https://commons.erau.edu/space-congress-proceedings/proceedings-1966-3rd/session-5/3

This Event is brought to you for free and open access by the Conferences at Scholarly Commons. It has been accepted for inclusion in The Space Congress ${ }^{\circledR}$

Proceedings by an authorized administrator of Scholarly Commons. For more information, please contact commons@erau.edu.

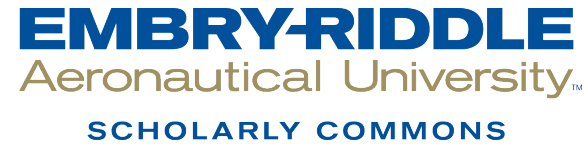


M. A. Barone

Brown Engineering Company, Inc. Huntsville, Alabama

\section{About the Author}

Mr. Barone is a graduate of Temple University with advanced work in Psychology and Mathematics and over 11 years experience in Human Factors. He has authored and developed reliability programs for documentation error analysis and as a management consultant has developed numerous job evaluation programs. Presently, he is a Section Chief in the Human Factors Branch, System Engineering Department, Brown Engineering Company, Inc., Huntsville, Alabama.

\section{Surmmary}

Presented in this paper is a methodology to evaluate, analyze, and predict critical human performance. The methodology is a novel approach towards evaluating potential human error. The aim of the Critical Human Performance and Evaluation Program (CHPAE) is to develop a methodology to control and minimize the natural subjectivity associated with evaluation programs. The typical approach of the CHPAE is; (1) analyze the system or task, (2) select evaluation factors, (3) establish and prevalidate a rating manual or check list, (4) perform an analysis and evaluation, (5) estimate potential error probabilities, and (6) perform critical comparison studies. Much work still remains to be done towards a complete and final validation of the program--partly because there is a variety of methods both computerized and manual that can be applied to quantify the evaluations and partly because of the need of large population statistics, other than experimental or selected source data to validate the error potential prediction of the plan. Regardless of the early limitations of the metric, the plan will perform a valuable human factors evaluation of a group of tasks, subsystems or systems.

\section{Introduction}

The evaluation and prediction of potential human error is one of the most perplexing and evasive problems facing the modern state-of-theart. By relative comparison with the technological progress of hardware failure prediction technology, the investigation and solving of problems involving equipment failures or unscheduled holds, where the breakdown of the human interface has been the causative factor, is today's most fertile area toward improving total systems effectiveness and systems reliability.
Systems reliability cannot be assessed by considering hardware and hardware alone. All facets of integrated hardware, $\mathrm{man} / \mathrm{machine}$, and/or extra-environmental factors must be considered. Also, rational consideration is required to take into account not only the potential probabilities of the beast's inhumanities to man, but also man's inhumanities to the sensitive beast.

\section{History of Past Research}

Very little is known about potential human error prediction; even less is known about the reliability metric describing the $\mathrm{man} / \mathrm{machine}$ interface.

Without sparing sophistication to either extreme, both qualitative and quantitative attempts at human factors prediction and analysis of probable human error have been proposed. Regardless of these attempts, human errors are continually being reported.

The following reports are typical of human error dilemma. Shapero and Bates (1960) published a report revealing the impact of human induced failures involved in military weapons systems. 1 This report states that:

a. Thirty-nine percent of 3,829 malfunctions related to weapons systems were classified as human initiated.

b. Twenty percent of 419 unscheduled holds were classified as human initiated.

c. The analysis of two systems using the Ballistic Missile Division Failure and Code List revealed 322 human initiated malfunctions in one system and 193 in the other.

A report by W. I. LeVan (1960) discloses the following facts: 2 (1) of nine Air Force programs reviewed, 20 and 53 percent of the field errors were caused by human failure, (2) of Army Satellite Programs, up to 60 percent of the failures were attributed to human error, and (3) of weapon, missile, and guidance systems, 12 to 45 percent of the failures were attributed to human error.

There is a well-defined requirement for a human factors potential error prediction, evaluation, or analysis program, especially one which is relatively easy to apply, versatile and 
unrestricted in its application, practical, and not overly complex in its formulation.

\section{Critical Human Performance, Analysis, and Evaluation Rationale (CHPAE)}

The CHPAE methodology employs system, task, and factor analysis in conjunction with correlated actual and/or experimental failure data to evaluate and establish a rated criticality rank of human performance. The criticality is based on the probability of successful human performance.

The CHPAE metric is a statistical analysis of the representative rated distributions and/or expression of computerized matrix techniques applied to the rated factor comparisons.

\section{Assumptions}

The as sumptions of the CHPAE methodology are:

a. Ideal potential human input interacting with ideal machine and/or environmental conditions facilitate the least probability of human error and the highest reliability.

b. Conversely, the worst possible human potential input with the worst possible machine and/or environmental conditions propagate the greatest probability of human error and the least reliability for success.

\section{Methodology Goals and Philosophy}

The goal of the CHPAE program is to present a methodology for evaluating critical human performance. which:

The philos ophy is to design a methodology

a. Provides a technical approach that systematically establishes a criticality rank of human performance.

b. Is both qualitative and quantitative, versatile in its application, and relatively easy to apply by both human factors personnel and reliability engineers.

c. Incorporates a methodology having the inherent capability to use manual or computer methods for the processing of data.

d. Preparing necessary mathematical models and procedures to predict the degradation the human element introduces to the system or subsystem.

\section{Objectives}

The objectives of the applied CHPAE methodology are to:

a. Establish a criticality rank related to human performance.

b. Predict personnel effectivity or probability of human induced failure related to operation, checkout, and/or maintenance of a system.

c. Identify and eliminate sources of potential critical human induced failures.

d. Estimate required check redundancy for most probable success.

e. Evaluate designs from a human factors or man-compatibility point of view.

f. Evaluate predesign concepts.

g. Provide inputs to training programs identifying and stressing areas of critical human performance.

h. Establish goals for optimum human reliability.

\section{Typical Technical Approach}

The methodology is basically applied as a program in three phases. The technique is versatile and is applicable to a system, subsystem, event, activity, or task. The evaluation or rating manuala can be tailor-made to a particular system, or developed as a generalized rating manual. The generalized approach would apply to a family of systems, subsystems, or even generalized to yield "ballpark" estimates of random activity.

Phase I of the methodology compriaes:

a. Analyzing the system,

b. Establishing the rating manual, and

c. Verifying the rating or evaluation manual. includes:

Phase II is the evaluation effort and

a. The actual rating, analysis, and evaluation.

b. Establishing the performance criticality.

c. Performing the overall syotems criticality study and analysis. 
Phase III is the documentation, maintenance, and follow-up phase. It also includes final test and validation of the project, and final validation of the rating manual.

\section{Pre-Validating the Rating Manual}

The CHPAE is a pre-validated critical factor approach to the evaluation and prediction of critical human performance. Pre-validation is accomplished by first developing a preliminary rating manual, selecting a representative sample, rating the sample, applying the preliminary manual, and then comparing the results to experimental data source or actual failure data. Figure 1 outlines the validating procedure.

\section{Developing the Evaluation Manual}

Development of the evaluation manual is preceded by project exploratory systems or task analysis. The purpose of the exploratory study analysis is to select representative critical factors which best represent the man/machine and/or man/environment interfaces. Candidate critical performance factors are first proposed in the preliminary evaluation manual. Typical candidate critical performance factors are shown in Table 1. The critical factors elected to be employed in the final evaluation manual are the factors which provide the optimum evaluation of the system or project and have the highest correlation with prediction of potential human error.

\section{Critical Factor Definition}

The factors selected are verbally defined and a rating assigned to the factors. The rating scale is by the degree of error confidence or probable error related to the degree of difficulty. Following definition of the factors and degrees, task and/or activities of experimental or actual data of knowa probabilities are slotted in their proper or estimated level in the defined rating scale. The slotted known or experimental probabilities in the rating scales are referred to as "inference marks". Figure 2 shows a typical definition of factor degree and inference marks used in the CHPAE approach.

The slotting of inference data of known ox validated task probabilities is a continuous updating effort. As the feedback procedure cranks more and more actual data back into the rating manual, the evaluation predictions become more confident and consistent.

\section{Value Weighting and Point Assignment}

Values apportioned to the factors are based on the criteria of optimum prediction for criticality ranking. The preliminary values are slotted, known, or estimated task probabilities.
After validation of the preliminary manual, the final proportionate value weightings assigned to the factors are dependent on their correlation and contribution or ability to predict a valid critical rank. This can be accomplished by multiple or partial correlation coefficients in conjunction with trial re-runs of the sample validation procedure, until the rating manual is calibrated to provide a valid critical rank.

\section{Evaluation Procedure}

The initial point of departure as to where to begin the evaluation is of no major importance. All activities of events will be summarized from the subtasks up through the subsystem and finally summarized and compared for the total system.

The evaluations can be performed for a task, a group of sub-tasks, or for an activity. In any event, a complete task analysis and study of all technical, environmental, tools; equipment or other affecting facets of the manl machine interface is required prior to the evaluation.

Pertinent information from the study and analysis is recorded on a typical rating specification form (See Figures 3 and $3 A$ ). The critical factors are rated by applying the evaluation manual and assigning related degrees and points. Rating consideration is given to all facets of the activity, and substantiating data is recorded to support the rating.

\section{CHPAE Metric}

The CHPAE model is an abstract matrix representation of the performed activity and the affecting $\mathrm{man} / \mathrm{machine}$ or $\mathrm{man} / \mathrm{machine} / \mathrm{environ-}$ ment factors. The abstract model is represented as a total two way classification matrix or a split matrix as shown in Table II. Table II delineates a typical activity matrix with 12 selected factors and the 10 tasks which comprise the activity.

\section{Variance Analysis}

The variance model is computerized as a $12 \times 100$ combined matrix with a subroutined split matrix $5 \times 100$ for the man affecting façtors and $7 \times 100$ split matrix for the machine/environmental affecting factors. The variance analysis is first performed on the total matrix and then subroutined to the split matrices.

The variance analysis model is represented as follows: ${ }^{3}$

$i=1.2 .3 . . . . r$

$Y_{i j}=\bar{u}+a_{i}+\tau_{j}+e_{i j}$

$\mathrm{j}=1,2.3 . \ldots \mathrm{c}$ 


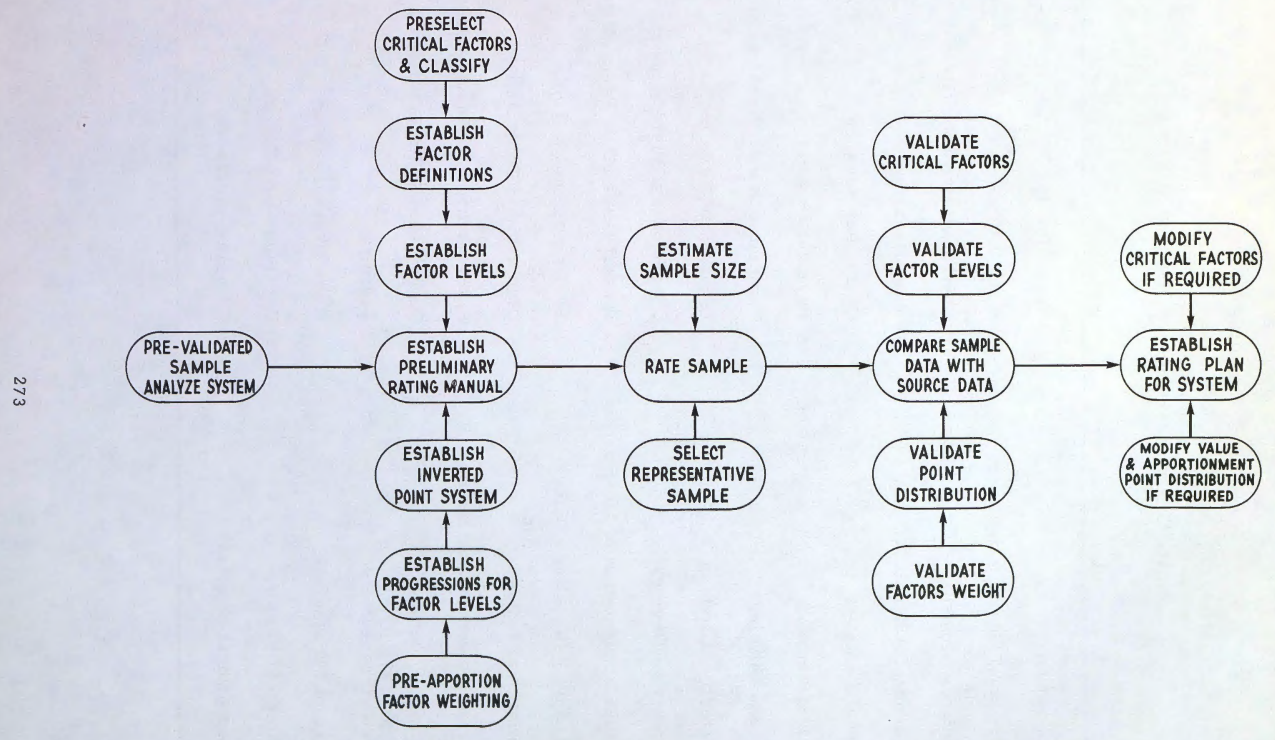

Figure 1. Pre-Validating Procedure 
Table I

Candidate Critical Performance Evaluation Factors

Motivation

Personnel Qualifications

Auditory Threshhold Criticality

Personnel Adaptation

Visual Demands

Mental Demands

Access Openings

Protective Clothing

Protective Devices

Visual Presentation of Information

Warning \& Signaling Devices

Mechanical Indicators

Special Systems Requirements

Human Dynamics

Crew Arrangement

Ease of Maintenance

Biological Factors

Occupational Factors
Accessibility

Work Space

Environmental Conditions

Work Hazards

Equipment Hazards

Physical Demand

Communications; Visual Aural

Lighting or Illumination

Operational \& Field Support

Special Demands \& Precautions

Test Equipment \& Tools

Displays and Controls

Anthropomorphic Requirements

Supervision \& Inspection

Training

Work Pressure

Documentation Errors

Engineering Change Errors 
The identification error factor appraises the probability that an error in identification will be committed when an object identified incorrectly and then treated as if it were the correct object. Consideration shall be given to evidence that suggests the frequency of errors of identification is much higher than any probable human error.

\begin{tabular}{|c|c|c|}
\hline DEGREE & FACTOR LEVEL DESCRIPTION & PTS. \\
\hline 1 & $\begin{array}{l}\text { Little or no probability of an identification error occurring } \\
\qquad \text { Inference Marks }(\overline{\mathrm{R}}=.975 \pm 2.5 \%) \\
\text { - Read and identify simple electrical or mechanical instrumentation } \\
\text { - Simple leak checks } \\
\text { General visual inspection } \\
\text { - Simple operational checks } \\
\text { - Identify items involving routine tasks } \\
\circ \text { Remove and replace black boxes } \\
\circ \text { Remove and replace standard piping (no complications) }\end{array}$ & 7 \\
\hline 2 & $\begin{array}{l}20 \% \text { confident that an identification error will occur at least once } \\
\qquad \text { Inference Marks }(\overline{\mathrm{R}}=.90 \pm 5 \%) \\
\text { Install complex subassemblies } \\
\text { Fault checks and isolation of detailed electronic instrumentation } \\
\text { Read and follow complex instructions }\end{array}$ & 18 \\
\hline 3 & $\begin{array}{l}25 \% \text { confident that an identification error will occur at least once } \\
\qquad \begin{array}{l}\text { Inference Marks } \\
(\overline{\mathrm{R}}=.75 \pm 5 \%)\end{array} \\
\text { - Highly complex instrumentation readings involving highly complex } \\
\text { systems } \\
\text { Highly complex troubleshooting }\end{array}$ & 28 \\
\hline 4 & $\begin{array}{l}40 \% \text { confident that an identification error will occur at least once } \\
\qquad \text { Inference Marks }(\overline{\mathrm{R}}=.60 \pm 5 \%) \\
\text { Consideration for redundancy or redesign of procedures required } \\
\text { to maintain reliability }\end{array}$ & 45 \\
\hline
\end{tabular}

Figure 2. Factor Definition 


\begin{tabular}{|c|c|c|c|c|}
\hline ACTIVITY TITLE: & $\begin{array}{l}\text { INSTALL S-IC WORK PLATFORM TO } \\
65836373 \text { PANEL SUPT. ASSEMBLY }\end{array}$ & \multicolumn{3}{|c|}{$\begin{array}{l}\text { ACTIVITY CODE: } 1261 \\
\text { TASK CODE: }\end{array}$} \\
\hline \multicolumn{2}{|l|}{ TASK TITLE : } & \multicolumn{3}{|c|}{$\begin{array}{l}\text { R-Inher: } .975 \\
\text { CRITICALITY: II }\end{array}$} \\
\hline ACTIVITY LOCATIO & N: S-IC INTERSTAGE & \multicolumn{3}{|c|}{ REDUNDANCY } \\
\hline FACTORS & \multicolumn{2}{|c|}{ SUBSTANTIATING DATA } & DEG & PTS \\
\hline MEMORY & \multicolumn{2}{|c|}{$\begin{array}{l}\text { PLATFORM SUBASSEMBLLES NOT DIFICULT TO INSTALL- } \\
\text { MINOR SUBASSEMBLIES }\end{array}$} & 2 & 8 \\
\hline ATTENTION & \multicolumn{2}{|c|}{$\begin{array}{l}\text { FITTING AND ALIGNMENT NOT DIFFICULT- MINOR } \\
\text { SUBASSEMBLIES }\end{array}$} & 1 & 0 \\
\hline IDENTIFICATION & \multicolumn{2}{|c|}{ ROUTINE TASK IDENTIFICATION REQUIREMENTS } & 1 & 7 \\
\hline INTERPRETATION & \multicolumn{2}{|c|}{$\begin{array}{l}\text { SIMPLE OPERATIONAL CHECKS } \\
\text { ROUTINE READING OF BLUE PRINTS }\end{array}$} & 1 & 7 \\
\hline PHYSICAL DEMAND & \multicolumn{2}{|c|}{$\begin{array}{l}\text { MODERATE PHYSICAL EFFORT - REQUIRES HANDLING } \\
\text { PLATFORM IN DIFFICULT WORK POSITION }\end{array}$} & 2 & 8 \\
\hline SAFETY OF OTHERS & \multicolumn{2}{|c|}{ HANDLING PLATFORM OVERHEAD } & 2 & 8 \\
\hline$x_{m} 6.3$ & \multicolumn{2}{|l|}{$\sigma_{m} 1.2$} & \multicolumn{2}{|c|}{$\begin{array}{l}\text { TOTAL } \\
\text { PTS. } 38\end{array}$} \\
\hline $\begin{array}{l}\text { OPERATION OR } \\
\text { PROCEDURES }\end{array}$ & \multicolumn{2}{|c|}{ SIMPLE ROUTINE DUTIES ASSEMBLING PLATFORMS } & 1 & 140 \\
\hline $\begin{array}{l}\text { WORKING } \\
\text { CONDITIONS }\end{array}$ & \multicolumn{2}{|c|}{$\begin{array}{l}\text { POSSIBLE HYPERGOL CONTAMINATION,ENVIRONMENT } \\
\text { CONTAINS POSSIBLE ELECTRIC HAZARDS }\end{array}$} & 3 & 95 \\
\hline $\begin{array}{l}\text { SPECIAL DEMANDS } \\
\text { \& PRECAUTIONS }\end{array}$ & \multicolumn{2}{|c|}{ NO SPECIAL TOOLS OR TRAINING } & 1 & 70 \\
\hline $\begin{array}{l}\text { OPERATIONAL } \\
\text { SUPPORT }\end{array}$ & \multicolumn{2}{|c|}{ CONSTANT MONITOR REQUIRED } & 2 & 65 \\
\hline COMMUNICATIONS & \multicolumn{2}{|c|}{$\begin{array}{l}\text { TELEPHONE LINE AVAILABLE-LITTLE OR NO } \\
\text { INTERFERENCE }\end{array}$} & 2 & 65 \\
\hline $\begin{array}{l}\text { EQUIPMENT } \\
\text { HAZARDS }\end{array}$ & \multicolumn{2}{|c|}{$\begin{array}{l}\text { EXERCISE CARE, HANDLING EQUIPMENT, TO PREVENT } \\
\text { DAMAGE TO FLIGHT CRITICAL ITEMS AND WIRING }\end{array}$} & 3 & 85 \\
\hline WORKING SPACE & \multicolumn{2}{|c|}{ WORK ENYELOPE ADEQUATE } & 3 & 55 \\
\hline ACCESSIBILITY & \multicolumn{2}{|l|}{ ACCESSIBILITY IS ADEQUATE } & 3 & 55 \\
\hline$X_{e} 78.7$ & \multicolumn{2}{|l|}{$\sigma_{\mathrm{e}} 26.6$} & \multicolumn{2}{|c|}{$\begin{array}{l}\text { TOTAL } 635 \\
\text { PTS. } 635\end{array}$} \\
\hline
\end{tabular}

Figure 3. Typical Rating Specification 


\begin{tabular}{|c|c|}
\hline SATURN V MAINTAINABILITY & ACTIVITY CODE: 1261 \\
\hline & TASK CODE: \\
\hline $\begin{array}{l}\text { ACTIVITY TITLE: INSTALL S-IC WORK PLAT- } \\
\text { FORM T0 } 65 B 36373 \text { PANEL SUPT. ASS'Y }\end{array}$ & TASK TIME: 15 \\
\hline TASK TITLE: & \\
\hline PERSONNEL REQUIRED : 2 & CRITICALITY: 11 \\
\hline LOCATION: S-IC INTERSTAGE & Rinh: -.975 \\
\hline $\begin{array}{l}\text { FUNCTIONAL OR ACTIVITY DESC } \\
\text { PLAN AND PERFORM ALL REQUIRED TASKS TO IN } \\
\text { WORK PLATFORMS. WORK IS PERFRORMED PRI } \\
\text { AND AFTER REMOVAL OF THE ARMING TOW }\end{array}$ & $\begin{array}{l}\text { IPTION } \\
\text { ALL THE S-IE INTERTANK } \\
\text { RT CRYOGENIC LOADING } \\
\text { R }\end{array}$ \\
\hline 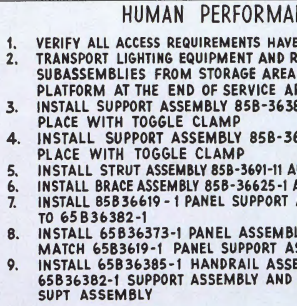 & 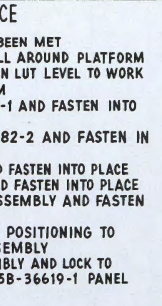 \\
\hline
\end{tabular}

Figure 3A. Typical Rating Specification 
Table II

Abstract Man/Machine Computer Matrix

Total Matrix

\begin{tabular}{|c|c|c|c|c|c|c|c|c|c|c|c|c|}
\hline Activity & \multicolumn{5}{|c|}{ Man } & \multicolumn{7}{|c|}{ Machine/Environment } \\
\hline \multirow[b]{2}{*}{ Task $i_{1}$} & $\mathrm{j}_{1}$ & $\mathrm{j}_{2}$ & $j_{3}$ & $j_{4}$ & $j_{5}$ & $j_{6}$ & $j_{7}$ & $j_{8}$ & $j_{9}$ & $\mathrm{j}_{10}$ & $\mathrm{j}_{11}$ & $\mathrm{j}_{12}$ \\
\hline & 1 & 1 & 1 & 1 & 2 & 1 & 2 & 3 & 1 & 1 & 1 & 1 \\
\hline Task $i_{2}$ & 1 & 1 & 2 & 2 & 1 & 1 & 2 & 2 & 1 & 2 & 1 & 1 \\
\hline Task $i_{3}$ & 2 & 1 & 1 & 2 & 2 & 1 & 3 & 1 & 2 & 3 & 3 & 3 \\
\hline Task ${ }_{4}$ & 2 & 1 & 1 & 2 & 2 & 1 & 1 & 3 & 2 & 1 & 1 & 2 \\
\hline Task $i_{5}$ & 1 & 1 & 1 & 2 & 1 & 1 & 2 & 1 & 2 & 1 & 2 & 2 \\
\hline Task i 6 & 1 & 1 & 2 & 1 & 1 & 1 & 2 & 2 & 2 & 1 & 2 & 2 \\
\hline Task i 7 & 2 & 1 & 2 & 1 & 1 & 1 & 2 & 1 & 1 & 1 & 2 & 3 \\
\hline${ }^{\text {Task i }}{ }_{8}$ & 1 & 2 & 1 & 1 & 1 & 2 & 1 & 3 & 1 & 1 & 1 & 1 \\
\hline Task $i_{9}$ & 1 & 1 & 1 & 2 & 2 & 1 & 1 & 3 & 1 & 1 & 2 & 1 \\
\hline Task $_{10}$ & & & & & & & & & & & & \\
\hline & & & & & & & & & & & & \\
\hline${ }^{i} \mathrm{n}$ & & & & & & & & & & & & \\
\hline
\end{tabular}


where: $\begin{aligned} & Y_{i j}=\text { The rating in the } i^{\text {th }} \text { task row and the } j^{\text {th }} \\ & \text { factor column. }\end{aligned}$

$\overline{\mathbf{u}}=$ General mean.

$a_{i}=$ Rating effect of the $i^{\text {th }}$ row level of the factor treatments.

$\tau_{j}=$ Rating effect at the $j^{\text {th }}$ column level of the factor treatments.

$e_{i j}=$ Random rating error

The following formula is applied to the matrix to analyze the variance of task probability ratings.

$u=\frac{\sum_{i j}\left(\bar{Y}_{i}-\bar{Y} \ldots\right)^{2} /(r-1)}{\sum_{i j}\left(Y_{i j}-\bar{Y}_{i}-\bar{Y}_{j}+\bar{Y} \ldots\right)^{2} /(r-1)(c-1)}$

where:

$s_{1}^{2}=\sum_{i j}\left(\bar{Y}_{i}-\bar{Y} \ldots\right)^{2}=\begin{aligned} & \text { Sum of the squares } \\ & \text { due to the factor treat }-\end{aligned}$ ments, $(r-1)$ degrees of freedom.

$S_{3}^{2}=\sum_{i j}\left(Y_{i j}-\bar{Y}_{i}-\bar{Y}_{j}+\bar{Y} \ldots\right)=$ Sum of the $_{\text {squares for total }}^{(4)}$ variance.

and:

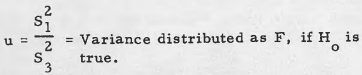

The variance analysis related to factor treatments and the activity is expressed as:

$$
u=\frac{\sum_{i j}\left(\bar{Y}_{i j}-\bar{Y} \ldots\right)^{2} /(c-1)}{\sum_{i j}\left(Y_{i j}-\bar{Y}_{i}-\bar{Y}_{j}+\bar{Y} \ldots\right)^{2} /(r-1)(c-1)}
$$

where:

$$
\begin{aligned}
& s_{2}^{2}=\sum_{i j}\left(\bar{Y}_{f_{j}}-\bar{Y} \ldots\right)^{2} /(c-1)= \text { Sum of squares }(7) \\
& \text { of task ratings }(c-1) \\
& \text { degrees of freedom }
\end{aligned}
$$

$s_{3}^{2}=$ Sum of total variance as in (4).

and:

$$
\mathrm{u}=\frac{\mathrm{S}_{2}^{2}}{\mathrm{~S}_{3}^{2}}=\text { Distributed as } \mathrm{F} \text { if } \mathrm{H}_{\mathrm{o}} \text { is true. }
$$

The computation of the CHPAE metric is accomplished by statistically comparing the rated distributions and statistical parameters of the total matrix and split matrices. Representative confidence curves are prepositioned such that an ideal rating of the interface would reflect little or no overlap of the confidence curves and that when $x_{2}-x_{1}=0$, the interface index would be highly critical.

By considering the variance of the scores, the inherent rated reliability of the interface $P_{\text {inh }}$ is formulated below:

$P_{\text {inh }}=\frac{\left(x_{2}-x_{1}\right)-K}{\sqrt{\sigma_{2}^{2}+\sigma_{1}^{2}}}=\frac{d_{t}}{\sigma_{t}}$

where:

$\left(u_{1}-u_{2}\right)=k$ or 0

$\mathrm{X}_{2}=$ Average Environmental Rating

$\mathrm{X}_{1}=$ Average Man Rating

$\sigma_{2}=$ Rating Variance - Environment

$\sigma_{1}=$ Rating Variance - Man

$d_{t}=$ Activity Margin

$\sigma_{t}=$ Total Variance

$\mathrm{u}_{1}=$ Arbitrary Ideal Population - Man

$\mathrm{u}_{2}=$ Arbitrary Ideal Population - Environment

The percent reliability, " $R$ ", is determined by referring calculated $P_{\text {inh }}$ to $t-T a b l e s$.

$R=100-Q(t-T a b l e)$

For assurance that (1) the probability of the specific points in the distribution curve actually overlap each other, a test of assurance can be applied to a probability of success, "P", and confidence level, " $C$ ", to yield a statistic of assurance, "T $\mathrm{A}$ ". follows:

Then the test of assurance $\left(T_{A}\right)$ is as

$T_{A}=\frac{P_{\text {inh }}-K}{\sqrt{1 / N+\frac{K^{2}}{2 N-1}}}$

where:

$P_{\text {inb }}=$ from $(1)$

$\mathrm{K}$ = from Chi Square Table 
A math model of the critical index computation is illustrated in Figure 4. The reliability index is extracted from output $A$.

\section{Performance Criticality Rank}

The CHPAE criticality rank is obtained by ranking the significance level of the rated inherent probability $P_{i n h}$. - probability of successful human performance.

The criticality scale is as follows:

$$
\begin{aligned}
& \text { Criticality I - Above } 0.1 \% \text { level } \\
& \text { Criticality II - } 1 \% \text { to } 0.1 \% \text { level } \\
& \text { Criticality III - } 5 \% \text { to } 1 \% \text { level } \\
& \text { Criticality IV - Below } 5 \% \text { level } \\
& \text { Criticality V - Below } 10 \% \text { level }
\end{aligned}
$$

\section{CHPAE Systems Approach}

The computation of the systems probabilities can be pooled and summarized up to the systems level. However, since the program carries a rated controlled judgment, the desirable confidence precision is best maintained by pooling up to the activity levels and posting the results to the systems criticality comparative analysis. This type of format chart is illustrated in Figure 5. Series, parallel, and redundant sub-tasks, tasks, activities, events, etc. must be considered in the task and activity pooling. Redundancy must also be considered in the comparative analysis.

\section{Application to Single or Random Activity - General Program}

An evaluation program for single or random activity can be accomplished by developing a generalized plan, including an evaluation manual with generalized factors which will rate most human activities. The general plan can have an open end to add or substitute one or five factors. In most cases, interpolation of the factors will suffice where the factors do not quite fit the task or activity.

\section{Computer Backup}

The CHPAE program has been designed to facilitate computer programming and computer support. It is highly desirable that computer time be requested if a large number of activities are to be evaluated. Computer application relieves the analyst of the cumbersome task of making statistical calculations, and provides backup support to non-math personnel such as psychologists, biologists, ahd human factors specialists.

\section{Conclusions}

The CHPAE program is a novel approach to rate the $\mathrm{man} / \mathrm{machine}$ interface.

The program is both qualitative and quantitative in design and sufficiently versatile for application to a wide variety of human tasks and activities.

Once established, the plan can be applied with relative ease by psychologists, physiologists, biologists, human factors specialists, and reliability engineers. It provides a valuable tool for evaluating critical human performance, performing human error analysis, evaluating system and hardware designs, performing maintainability analysis, determining training requirements, and evaluating human operational requirements. The plan is designed also to facilitate computer programming and calculation backup.

The CHPAE program has been designed to control and minimize the natural subjectivity associated with evaluation programs. The metric is in terms of the probable potential human error and the probable significance of the rated reliability.

\section{Glossary}

Analysis of Variance - The magnitude of rated or estimated factor differences and the extent to which they differ from the residual mean square as a test of hypothesis that such differences are compared with the $5 \%$ and $1 \%$ fiducial levels of the standard $\mathbf{F}$ distribution.

CHPAE Matrix - A grid of classified man/ machine critical factors.

CHPAE Metric - A matrix analysis of rated probability estimates and varients; one distribution representing man's critical rated factors and one distribution representing the rated environmental varients. The variance analysis of the rated factors establish within confidence precision, the percentage of rated potential error in a particular activity or task.

CHPAE Model - A statistical abstract or schematic representation of the man/machine affecting factors and/or man/machine/envir onment interface.

CHPAE Redundancy - The number of repeated performances required in a given sample in order to assure one completely successful performance.

Critical Factor - A performance factor which, if not performed in accordance to correct procedure or design requirements, has the 


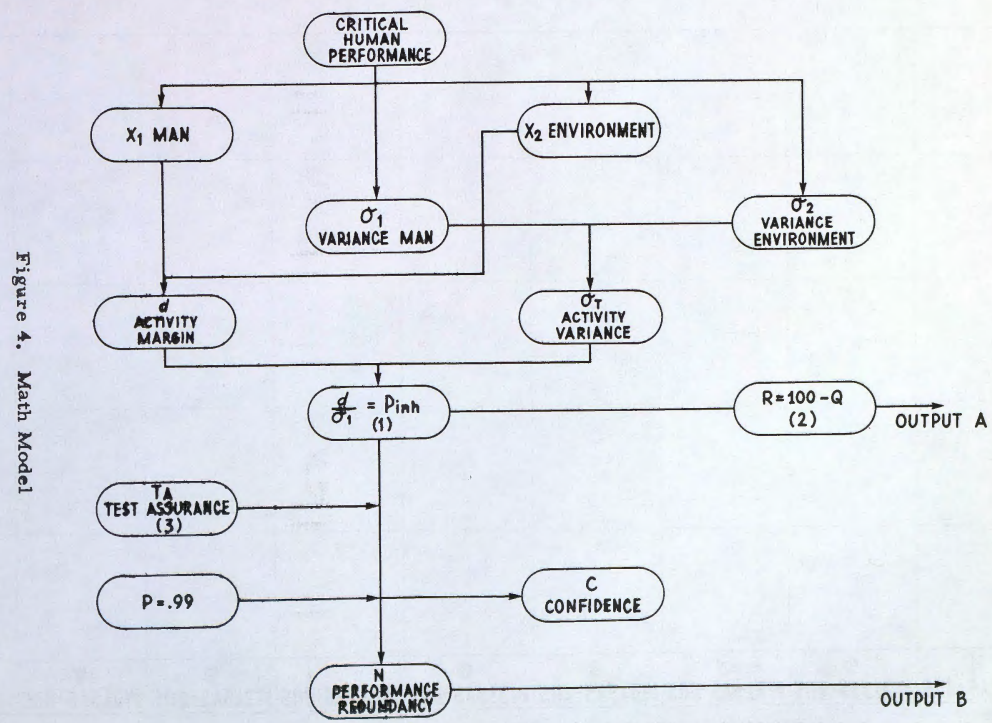




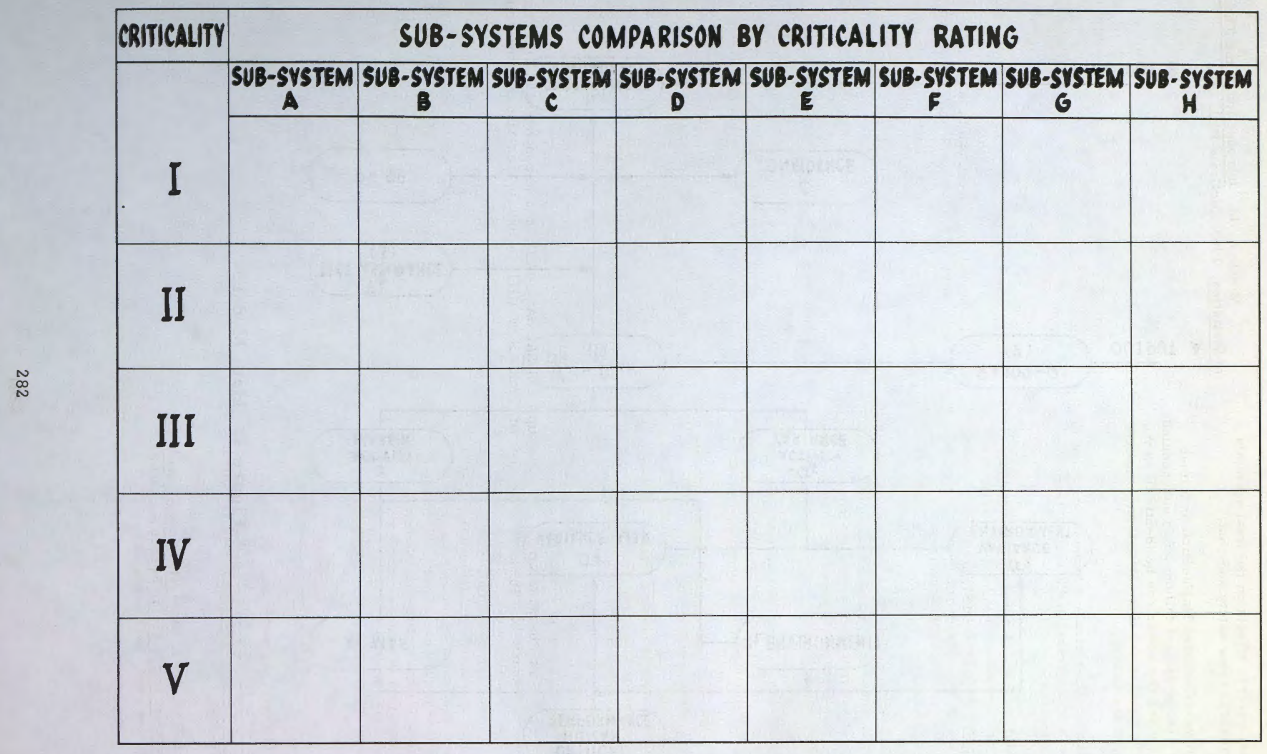

Figure 5. Systems Criticality Comparison Matrix 
greatest adverse effects on the total system's performance, crew safety and cost.

Human/Initiated Malfunction or Human Error - On equipment failure or an unscheduled hold in which the human can be identified as the causitive agent in the immediate train of events leading to the failure.

Human Operation - A human component in a process which translates a system from one state to another.

Malfunction - A general term used to denote the occurence of failure of a product to give satisfactory performance. In this report, malfunctions are considered to include equipment failures, procedural failures and unscheduled holds.

Man/Machine Interface - Assumed line of interaction between man and machine. Systems where man and machines are interacting together in a given environment to achieve given objectives.

Reliability - The probability of adequate performance of a specified function or functions for a specified time in a given environment.

Statistical Parameter - A representative statistical value or estimator.

System Representative Factor - A constant or variable factor which represents an affecting man/machine/environment characteristic of the system.

Task Analysis - An analytical process employed to determine the demands which human and machine components make upon each other in a given operational context. Task analysis usually involves (1) Identification of performed sequence of operations, (2) Identification of human and equipment components related to analyzed tasks, (3) Analysis of man/machine interaction, (4) Evaluation of performance time and, (5) Analysis of affecting factors such as environmental conditions, hazard to men and equipment, malfunctions, potential human error and others.

\section{References}

1 Shapero, A. and Bates, C., Jr. A Method for Performing Human Engineering Analysis of Weapon Systems, WADC Technical Report 59-784.

2 LeVan, W. I. Analysis of the Human Error Problem in the Field, Report No, 7-6093004,9 June 1960, Bell Aerosystems Co.
3 Mood, A. M. Introduction to the Theory of Statistics, 1963, McGraw-Hill, Inc. 